\title{
The sociocultural health behavioral model and disparities in colorectal cancer screening among Chinese Americans
}

\author{
Grace X Ma ${ }^{1,2}$, Min Qi Wang ${ }^{3}$, Xiang S Ma ${ }^{2,4}$, Giyeon $\mathrm{Kim}^{5}$, Jamil Toubbeh², Steven Shive ${ }^{2,6}$ \\ 1. Department of Public Health, College of Health Professions, Temple University, Philadelphia, PA, USA. 2. Center for \\ Asian Health, Temple University, Philadelphia, PA, USA 3. Department of Public and Community Health, University of \\ Maryland, College Park, Maryland, USA. 4. School of Medicine, Temple University, Philadelphia, PA. 5. Center for Mental \\ Health and Aging, Department of Psychology, The University of Alabama, USA. 6. Department of Health, East Stroudsburg \\ University, East Stroudsburg, PA, USA
}

Correspondence: Grace X. Ma, PhD, Professor of Public Health. Address: Department of Public Health, Director of Center for Asian Health, College of Health Professions, Temple University, 913 Ritter Annex, 1301 Cecil B Moore Ave., Philadelphia, PA, USA 19122-0843. Email: grace.ma@temple.edu.

Received: December 21, 2012

DOI : $10.5430 /$ jnep.v3n7p129
Accepted: January 24, $2013 \quad$ Online Published: J une 7, 2013

URL: http://dx.doi.org/10.5430/jnep.v3n7p129

\section{Abstract}

Objective: The purpose of this study was to validate a Sociocultural Health Behavior Model using a structural equation analysis to determine the direction and magnitude of the interdependence of model components in relation to health behavior associated with colorectal cancer (CRC) screening among Chinese Americans.

Methods: A cross-sectional design included a sample of 311 Chinese American men and women age 50 and older. The initial step involved use of confirmatory factor analysis which included the following variables: access/satisfaction with health care, enabling, predisposing, cultural, and health belief factors. Structural equation modeling analyses were conducted on factors for CRC screening.

Results: Education and health insurance status were significantly related to CRC screening. Those with less than a high school education and without health insurance were more likely to be "never screened" for CRC than those having more education and health insurance. The path analysis findings also lend support for components of the Sociocultural Health Belief Model and indicated that there was a positive and significant relationship between CRC screening and the enabling factors, between cultural factors and predisposing, enabling, and access/satisfaction with health care factors and between enabling factors and access/satisfaction with health care.

Conclusions: The model highlights the significance that sociocultural factors play in relation to CRC screening and reinforced the need to assist Chinese with poor English proficiency in translation and awareness of the importance of CRC screening. The use of community organizations may play a role in assisting Chinese to enhance colorectal cancer screening rates.

\section{Key words}

Colorectal cancer, Cancer screening, Chinese Americans, Sociocultural health behavior model, Structural equation modeling 


\section{Introduction}

Colorectal cancer (CRC) is the third leading type of cancer and is the third leading cause of cancer death in both men and women in the U.S ${ }^{[1]}$. CRC is the second most commonly diagnosed cancer among Asian Americans, and is the third highest cause of cancer related mortality in this population ${ }^{[2]}$. Although CRC can occur at any age, it is more likely to occur among older people. Beginning at age 50, for both men and women at average risk for developing colorectal cancer, the American Cancer Society recommends use of one of the following screening methods for polyps and cancer: flexible sigmoidoscopy every 5 years, colonoscopy every 10 years, double contrast barium enema every 5 years, and/or CT colonography (virtual colonoscopy) every 5 years. In addition, the guidelines' recommend a fecal occult blood test (FOBT) every year and fecal immunochemical test (FIT) every year. Colonoscopy should be done if test results are positive. For FOBT or FIT used as a screening test, the take-home multiple sample method should be used ${ }^{[3]}$.

An objective of Healthy People 2020 is to increase to $70.5 \%$ the proportion of Americans age 50 and older who receive colorectal screening according to the most recent guidelines. The MMWR report states that for all Americans age 50 and over, colorectal cancer screening was $58.6 \%{ }^{[4]}$. Colorectal cancer screening was significantly lower among Asians than among whites and blacks. A study by Jerant and colleagues (2008) found that only $33.8 \%$ of Asian Americans ( $=787$ ) had either endoscopy or FOBT. This study utilized linked data from the 2001-2005 Medical Expenditure Panel Survey (MEPS) and the 2000-2004 National Health Interview Survey (NHIS) ${ }^{[5]}$. A study by Sabrina and colleagues conducted among 1,771 Asian Americans and non-Latino Whites, age 50 and older, found that non-Latino Whites had the highest CRC screening rate of either FOBT (58\%) and endoscopy(57\%), or both (75\%) and the lowest rates for Asian Americans, respectively, $38 \%, 42 \%$ and $58 \%{ }^{[2]}$. A study by Maxwell, Crespi, Antonio, and Lu (2010), which examined disparities in colorectal cancer screening among five Asian ethnic groups in California, utilizing data from the California Health Interview Survey, found that the prevalence of screening among all Asian groups was consistently 11 percentage points lower than among the overall population in the years 2001, 2003, and 2005 (58\% versus $74 \%, 59 \%$ versus $70 \%$ and $62 \%$ versus $73 \%$, respectively), and 16 percentage points lower than whites. However, analysis of the specific Asian subgroups revealed that Japanese Americans had the highest prevalence of colorectal cancer screening with age- and genderstandardized levels of 71\%,72\%, and 77\% in 2001, 2003, and 2005, respectively, while Korean Americans had the lowest, with levels of $49 \%, 43 \%$, and $33 \%$. The other groups, including Chinese Americans, were at intermediate levels. The authors conclude that these findings highlight the importance of disaggregating Asian American subgroups when monitoring health indicators to avoid masking differences among them ${ }^{[6]}$.

Reported barriers to CRC screening in the general population include lack of knowledge, confidence, negative attitudes toward and fear of the findings of the tests, and lack of social support and physician recommendation ${ }^{[7-9]}$. While similarities in barriers between the general population and Chinese Americans exist, these studies highlight some differences, a number of which are attributed to acculturation factors and a general lack of knowledge about screening and the US health delivery system setting. A study by Sun and colleagues found that FOBT screening within the last 12 months was associated with fewer years of residency in the US, concerns about test results, and a higher level of perceived susceptibility of Chinese Americans to CRC. The study revealed that those who had sigmoidoscopy within the last 5 years had higher levels of education, were less anxious about test results, and had significantly lower levels of perceived susceptibility to $\mathrm{CRC}{ }^{[9]}$. Choe and associates, using qualitative analysis, identified factors that appear to facilitate CRC screening among Chinese Americans. These included rapport with a health care provider, social support, having health coverage, family members recommending the screening procedure, and physician recommendation. Major barriers identified in the study were difficulty with English, and embarrassment to discuss CRC through an interpreter, among others ${ }^{[10]}$. A study by Tang and colleagues illustrated the importance of physician recommendation and level of acculturation in CRC screenings ${ }^{[1]}$. The study by Maxwell et al, discussed above, showed that the proportion of Chinese Americans not up to date with colorectal cancer screening (past 10 years for endoscopy, past 12 months for FOBT) reporting doctor recommendation for screening in past year was $0.26(\mathrm{~N}=67 / 255){ }^{[6]}$. A study among Chinese Americans by Yip and associates (2006) did not find any significant socio-demographic factors related to CRC screening between those who had FOBT, sigmoidoscopy, and/or colonoscopy and those who did not within the last 12 months. 
Structural Equation Modeling (SEM) has been used in studies related to health problems such as minority youth substance use, HIV risk reduction intervention for injection drug users in treatment, stress reduction, racial/ethnic disparities in knowledge of HIV testing and treatment and other problems ${ }^{[12-15]}$. A few studies have used SEM modeling in examination of cancer related behaviors or outcomes such as cancer survivorship, communication among medical staff and families of cancer patients, intention to obtain genetic tests for colon and cervical cancer ${ }^{[16-18]}$. This type of modeling offers some advantages in examination of factors in cultural and ecological approaches ${ }^{[19]}$. The structure of relationships among a set of factors can be tested ${ }^{[20]}$, there is increased statistical control over random measurement error and measurement biases $^{[19]}$, and examination of interrelated constructs can occur without the disadvantages of a multivariate analysis of covariance approach ${ }^{[21]}$. Since colorectal cancer screening behavior is influenced by multiple factors, there is a need to identify these interrelationships and pathways among these factors. Often the role of cultural factors is seldom included in health behavior analyses.

The purpose of this study was to validate the Sociocultural Health Behavior Model (SCHBM) ${ }^{[22]}$ using Structural Equation Modeling Analysis to determine the direction and magnitude of the interdependence of the SCHBM components in relation to screening and health services utilization for colorectal cancer among Chinese Americans. Figure 1 represents a Sociocultural Health Behavior Model (SCHBM) ${ }^{[22]}$ that identifies and describes the relationships between and interactions among various factors that guide health behavior. The research-based model identifies six major factors that impact decision-making in health-seeking behaviors that lead to health care utilization. These include predisposing factors (e.g., demographic and social characteristics), cultural factors (e.g., health perceptions and beliefs, psychological status within the context of culture), needs factors (e.g., urgency of care (based on family health history, hierarchy of health care), enabling factors ( e.g., health coverage, communication, transportation), environmental/health systems factors (e.g., barrier-free health care facilities, resource availability), and family/social support factors (e.g., responsible and caring family and community). Although the SCHBM emphasizes the centrality of sociocultural factors in health behavior, it is the interaction of these factors that ensures a particular health behavior leads to a desirable outcome, namely health care utilization.

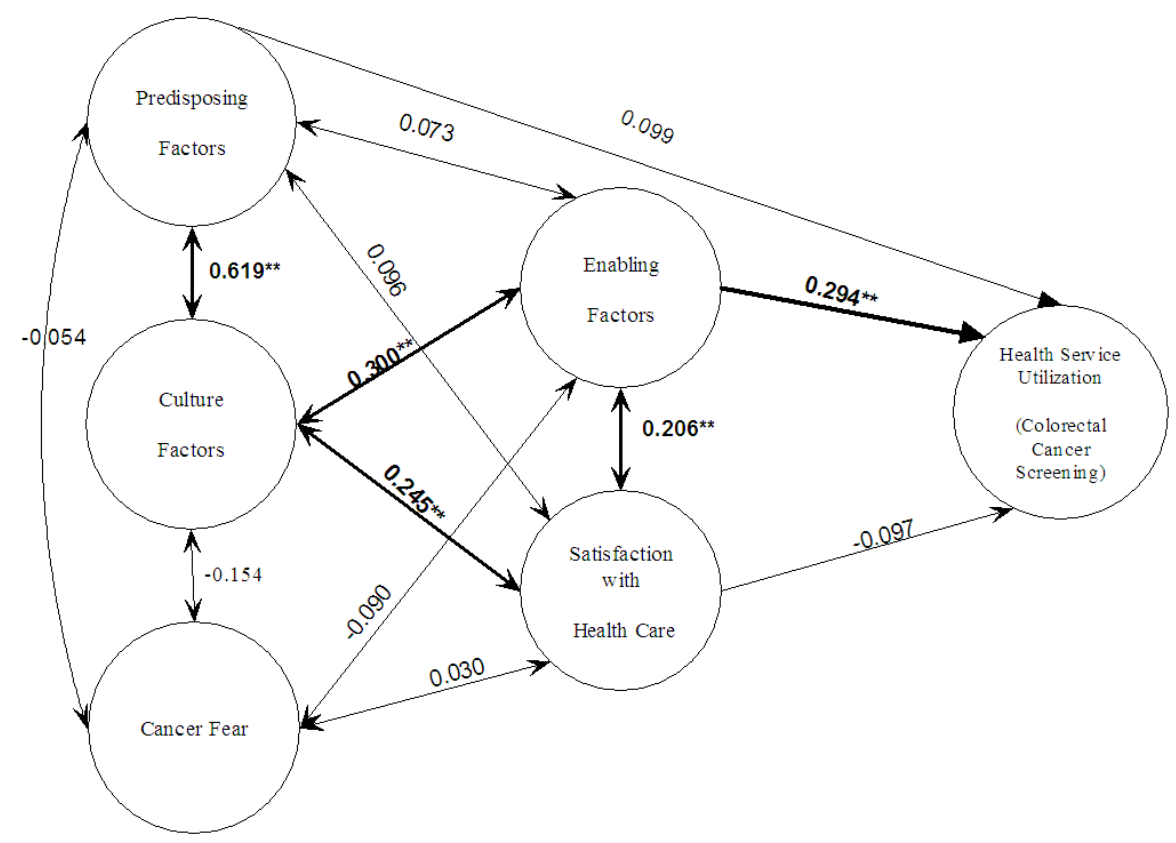

Figure 1. Path coefficients and their significance from the structural equation modeling analysis $(\mathrm{N}=311)$. Note CFI $=0.948 ;$ TLI $=0.968 ;$ RMSEA $=0.055$. Unstandardized estimates are shown. Colorectal Cancer Screening is coded $1=$ no, $2=$ yes. 


\section{Methods}

\subsection{Sample}

This study was part of a larger study which included a mixed ethnic sample of Chinese, Korean, Vietnamese, and Cambodian Americans. The sample was derived from a current list of 111 Asian American community organizations in the greater Philadelphia, PA area, New Jersey, and New York City. The organizations were identified by the Asian Community Cancer Coalition and staff of Temple University’s Center for Asian Health's Community Network Program. All identified organizations were in locations that maximized the coverage of Asian Americans across ethnicity, age, and socioeconomic status. A random sample of organizations $(\mathrm{N}=52)$ was selected as clusters from the list of 111 organizations. The selected organizations were stratified based on the four ethnic/language groups. A proportional allocation procedure of assigning the sample size proportionally to the subgroups size was used ${ }^{[23]}$. Of the 2,098 participants who agreed to participate in the study, 2,011 completed the study for a response rate of $95.9 \%$. The high response rate is partially due to the use of in-person data collection approach. The overall sample consisted of 2,011, distributed ethnically as follows: 923 Chinese (45.9\%), 384 Korean (19.1\%), 364 Vietnamese (18.1\%), and 340 Cambodian (16.9\%). Because the American Cancer Society recommends the colorectal cancer screening beginning at age 50 for both men and women, this study excluded those below age 50. The final study sample used in this study consisted of 311 Chinese male and female participants.

\subsection{Design and data collection procedures}

A cross-sectional research design was used in the study. All data were collected at organizational sites. Data collection administration training was provided to all survey administrators as well as to onsite bilingual translators. The survey was administrated using a one-on-one instruction method. Language assistance was provided as needed. Participants had the option of responding to the survey in English or in their native language. Duration of the survey was about 25 minutes.

\subsection{Measurements}

A 95-item multi-lingual questionnaire was developed by the Center for Asian Health research team, back-translated, and pilot-tested in separate, non-participating ethnic communities for reliability, validity, and cultural appropriateness.

The list of survey items used in the SEM and their alpha reliability coefficients presented in Table 1 are described below:

Satisfaction with health care: Seven items assessed a respondent's perceptions of their health care and doctors' services. The response categories were on a 5-choice scale: "poor," "fair," "good," "very good," and "excellent."

Enabling factors: The enabling factors were measured with three questions: "Do you currently have health insurance?"; "Do you have a primary health care provider to go to when you are sick?" and "How many times did you visit your current primary physician in the last 12 months?" The response categories were a binary choice (no/yes) for the first two questions. The third question was an ordinal scale with four choices: "never", "1-2 times", "3-4 times" and "5 or more times".

Predisposing factors: The predisposing factors measured the educational level of the participants, including their highest grade of school completed and their years of education completed.

Cultural factors: The cultural factors included participants' English proficiency and their level of information seeking (Internet use). The response categories were "not at all" to "very well" for English speaking and a binary choice (no/yes) for Internet use. 
Cancer fear factor: The cancer fear factor reflects the fear of having a bad cancer test result and whether the participants felt embarrassment about the possibility of having cancer. The response categories were a binary choice (no/yes).

Table 1. Parameter Estimates for Hypothesized Measurement Model

\begin{tabular}{|c|c|}
\hline $\mathrm{N}=311$ & Factor Loading \\
\hline \multicolumn{2}{|l|}{ Satisfaction with Health Care } \\
\hline Arrangements for making appointments for medical care & 1.000 \\
\hline Length of time waiting to see doctor at the office & 0.919 \\
\hline Length of time between making an appointment for care and visit & 0.953 \\
\hline Rating of care at your medical group & 0.855 \\
\hline Convenience of location of the doctor's office & 0.904 \\
\hline Access to medical care whenever needed & 0.934 \\
\hline Quality of care from your physician & 0.855 \\
\hline \multicolumn{2}{|l|}{ Enabling factor } \\
\hline Currently have health insurance & 1.000 \\
\hline Have a primary health care provider & 1.076 \\
\hline Number of times visited current primary physician in the last 12 months & 0.515 \\
\hline \multicolumn{2}{|l|}{ Predisposing factor } \\
\hline Highest grade of school completed & 1.000 \\
\hline Years of education completed & 2.596 \\
\hline \multicolumn{2}{|l|}{ Cultural factor } \\
\hline Use of the Internet for sources of information & 1.000 \\
\hline Fluency of speaking English & 0.945 \\
\hline Speak Native Asian language at home & 0.363 \\
\hline \multicolumn{2}{|l|}{ Cancer fear factor } \\
\hline Fear of getting a bad test result & 1.000 \\
\hline Embarrassment/shame & 1.458 \\
\hline
\end{tabular}

\subsection{Statistical analysis}

Model description: Latent model analyses were conducted using Mplus software. The models were covariance structural models with multiple indicators for all latent constructs. The analysis employed a 2-step procedure using maximum likelihood estimation. The first step was confirmatory factor analysis to test the measurement model. A measurement model describes the nature of the relationship between a number of latent variables and the observed variables corresponding to each of the constructs. The second step tested the structural model, depicted in Figure 1 in the results section. This step represents the theoretically based model in which the relationships among exogenous variables (those variables with both emanating paths and receiving paths) and endogenous variables (those variables with mostly receiving paths) can be seen. The dependent factor is a binary variable: never screened vs. screened. Using ordinal and dichotomous indicators is a very common practice in SEM literature. This practice is based on the assumption that the underlying construct represented by the dichotomous variables are continuous. A tetrachoric correlation was created instead of Pearson correlations for the SEM analysis ${ }^{[24]}$.

Model fit tests: Multiple indices were used to test the model fit, and they include the following: comparative fit indices (CFI), where the value of 0.90 or higher is considered acceptable ${ }^{[20]}$; Tucker-Lewis Index (TLI), where the value of 0.90 or higher is considered acceptable ${ }^{[20]}$; and the root mean square error of approximation (RMSEA), with the value below 0.08 indicating a good fit ${ }^{[25]}$. 


\section{Results}

\subsection{Sample characteristics}

Table 2 summarizes sample characteristics regarding colorectal cancer screening status. Education was significantly related to screening status, $\chi^{2}(1)=13.28, p<.01$. For Chinese with less than a high school education, $75.3 \%$ reported never-screened compared to $62.0 \%$ with high school or higher education who reported never-screened. Screening status was significantly related to health insurance, $\chi^{2}(1)=6.16, p<.05$. Of those without current health insurance, $77.9 \%$ reported never-screened compared with $61.7 \%$ of those with health insurance reporting never-screened. Gender, marital status, annual household income, and employment status were not significantly related to colorectal cancer screening status $(p>.05)$.

\subsection{Measurement model}

The factor loadings for the indicator variables associated with the constructs are presented in Table 1. The factor loadings are equivalent to standardized regression weights for predicting observed variables from latent constructs. The $t$ scores obtained for the coefficients in Table 2 were all significant except for one variable (Embarrassment/Shame). The magnitude of the factor loadings and their significance provided evidence to support the convergent validity of the indicators. Overall, the model fit indices and the factor loadings supported the reliability and validity of the constructs for their indicator variables. It was concluded that the theoretical constructs hypothesized to exist at the level of latent factors were assessed with an acceptable degree of precision and that the observed variables were adequate indicators of these factors.

Table 2. Colorectal Cancer Screening Status by Demographics of Chinese Americans $(\mathrm{N}=311)$

\begin{tabular}{|c|c|c|}
\hline & Never screened $(\mathrm{N}=203)$ & Screened $(\mathrm{N}=108)$ \\
\hline \multicolumn{3}{|l|}{ Gender } \\
\hline Male & 70.5 & 29.5 \\
\hline Female & 61.9 & 38.1 \\
\hline \multicolumn{3}{|c|}{ Current Marital Status } \\
\hline Unmarried & 67.8 & 32.2 \\
\hline Married & 64.7 & 35.3 \\
\hline \multicolumn{3}{|l|}{ Highest Degree** } \\
\hline$<$ High School & 75.3 & 24.7 \\
\hline$>$ High School & 62.0 & 38.0 \\
\hline \multicolumn{3}{|l|}{ Annual Income } \\
\hline$<\$ 10,000$ & 66.3 & 33.7 \\
\hline$\$ 10,000-\$ 30,000$ & 64.2 & 35.8 \\
\hline$>\$ 30,000$ & 69.2 & 30.8 \\
\hline \multicolumn{3}{|l|}{ Employment } \\
\hline Employed & 67.4 & 32.6 \\
\hline Unemployed & 62.0 & 38.0 \\
\hline \multicolumn{3}{|c|}{ Current Health Insurance* } \\
\hline No & 77.9 & 22.1 \\
\hline Yes & 61.7 & 38.3 \\
\hline
\end{tabular}

$* p<.05$ from chi square test; $* * p<.01$ from chi square test 


\subsection{Structural model}

The hypothesized model and the maximum likelihood estimates for the parameters of the model are presented in Figure 1. For all figures presented in this section, the constructs were coded in the same direction: a positive path coefficient indicates that it is more likely to be associated with cancer screening.

The path coefficients indicate the direction and magnitude of the associations. The enabling factors showed a positive and significant relationship with the screening factor (coefficient $=0.294, t=2.651, p<.01$ ). The significant path coefficient indicates that participants with health insurance, a primary health care provider, and frequent primary physician visits were more likely to have had colorectal cancer screening. None of the other factors was significantly related to the screening factor. The cultural factors were not directly related to cancer screening. However, they were significantly related to the enabling factors as well as the satisfaction with health care factor. The $\mathrm{R}^{2}$ value provides explained variance among construct variables. Overall, $9 \%$ of the colorectal cancer screening was explained by the model.

The hypothesized model and the maximum likelihood estimates for the parameters of the model were further conducted with males (see Figure 2) (male sample $=122)$ and females (see Figure 3) (female sample $=189$ ) separately. The purpose of conducting the gender breakdown model was to see if overall model was robust and also if there were differences between male and female samples. The enabling factors showed a more positive and significant relationship with the screening factor (coefficient $=0.487, p<.01$ ) for males than the overall model, while the path coefficient $(0.156)$ for females became non-significant, $p>.05$. The cultural factors were significantly related to the enabling factors (coefficient $=$ $0.491, p<.01$ ) and the satisfaction with health care factor (coefficient $=0.341, p<.01$ ), with both coefficients greater than the corresponding coefficients in the overall model. For females, these two coefficients, though still significant, showed smaller magnitude than the male model and the overall model. Other coefficients for both male and female models were somewhat consistent with the overall model. The $\mathrm{R}^{2}$ value indicated that $16.4 \%$ of the male colorectal cancer screening was explained by the model while for females, the $\mathrm{R}^{2}$ value was $2.4 \%$.

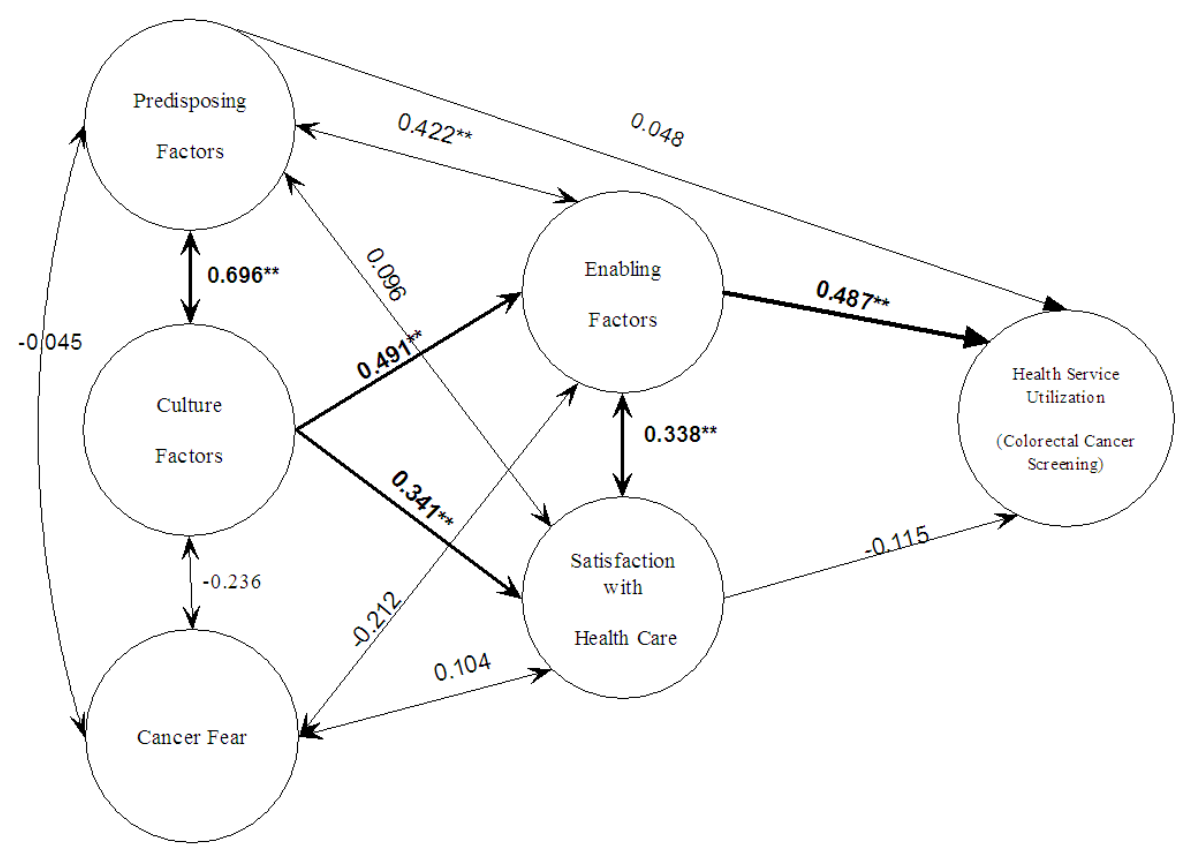

Figure 2. Path coefficients and their significance from the structural equation modeling analysis for the male sample $(\mathrm{N}=122)$.

Note. $\mathrm{CFI}=0.983 ; \mathrm{TLI}=0.979 ; \mathrm{RMSEA}=0.024$. Unstandardized estimates are shown. Colorectal Cancer Screening is coded $1=$ no, $2=$ yes. 


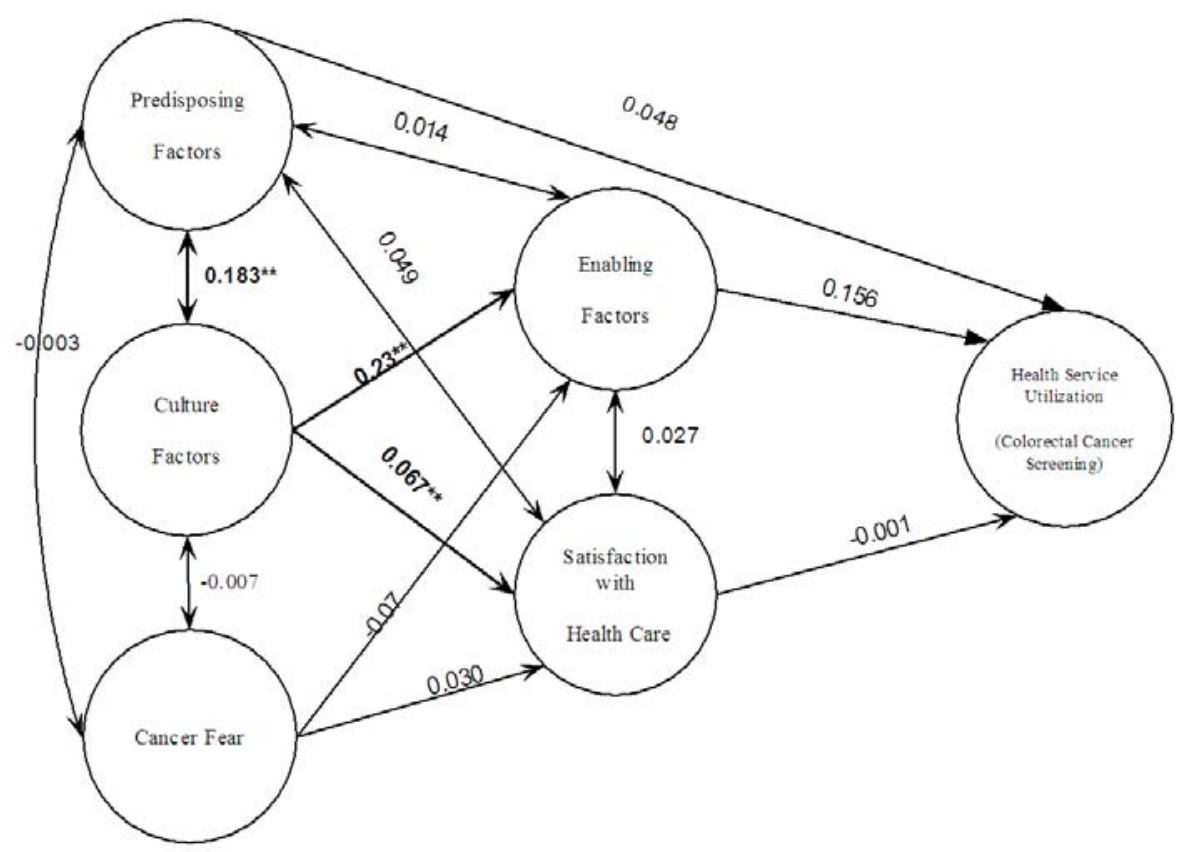

Figure 3. Path coefficients and their significance from the structural equation modeling analysis for the female sample $(\mathrm{N}=189)$.

Note $\mathrm{CFI}=0.964 ; \mathrm{TLI}=0.953 ; \mathrm{RMSEA}=0.046$. Unstandardized estimates are shown. Colorectal Cancer Screening is coded $1=$ no, $2=$ yes.

\section{Discussion}

The purpose of this study was to validate a SCHBM using a structural equation analysis to determine the direction and magnitude of the interdependence of model components in relation to health behavior associated with colorectal cancer (CRC) screening among Chinese Americans. Specifically, the SEM was used to determine the relationship and multiple levels of influence of predisposing, enabling, cultural, environmental, family and social support and health system factors underlying CRC screening.

Overall, the SEM analysis offered further insights into and support for a multilevel sociocultural approach to understanding the interrelationships between access and/satisfaction with health care that leads to CRC screening on the one hand, and those predisposing, enabling and cultural/factors that either facilitate or impede screening, on the other hand, among Chinese Americans. With the exception of embarrassment/shame, factor loadings were significant for all factors and showed a positive and significant relationship with screening for CRC (see Table 1). Chinese Americans with more than a high school education, had health insurance and a primary care provider whom they visited frequently, and those who had access to and were satisfied with health care, were more likely to be screened for CRC than those who did not have these enabling factors. Other studies have shown that Asians with lower socioeconomic status and those with less education are less likely to get screened ${ }^{[5,6,26-31]}$. SEM analysis confirmed our own previous observations and those of others ${ }^{[9,32-35]}$.

The SEM path analysis findings also lend support for components of the SCHBM and indicated that there was a positive and significant relationship between CRC screening and the enabling factors, between cultural factors and predisposing, enabling, and access/satisfaction with health care factors, and between enabling factors and access/satisfaction with health care (see Figure 1). In general, if Chinese were able to access health care and had a primary care provider, they were more likely to get screened. There were a number of factors which were loaded heavily under access/satisfaction with health 
care. These factors included being able to make an appointment, not having to wait long, the providers were in a convenient location, and the participants rated their provider highly. The cultural factors were significantly related to the predisposing, enabling, and satisfaction with health care factors. Chinese Americans who perceived they were fluent in English and used the internet as a source of information were more likely to be screened than those who were not fluent or did not use the internet. The model accounted for $9 \%$ of the variance in CRC screening.

When comparing the results of the male and female sample, an interesting finding surfaced. For males, the cultural factors were significantly related to the enabling factors which were significantly related to the health care utilization and was consistent with findings from the overall sample. However, for females, the cultural factors were significantly related to the enabling factors, but the enabling factors were not significantly related to the health care utilization. The explanation of this difference might be that many Asian countries are a patriarchal society in which the male is the primary authority figure central to the family ${ }^{[36]}$. In patriarchal society, males hold greater authority than females in decision making within the family including the decision for health care utilizations. It is hopeful that these findings could be further examined in future studies.

The SCHBM highlights the significant role that socio-cultural factors play in CRC screening and their significant relationship with enabling factors, e.g., higher educational level and health insurance. We cannot, of course, rule out other factors influencing screening. It is interesting to note that while other studies have found that acculturation and English fluency were correlated with higher rates of screening among Chinese Americans, this study did not find a direct relationship between acculturation and fluency and CRC screening ${ }^{[10,34,35]}$. We did however find that acculturation was significantly correlated with the predisposing, enabling, and health care satisfaction factors. These findings indicate that culture may be indirectly related to those factors which influence a Chinese person's decision to get screened. By the same token, speaking English may be correlated with a person's education level, ability to obtain a job which provides medical insurance, having a health care provider, and subsequent satisfaction with their health care experience. This finding reinforces the necessity to assist Chinese who have poor English language skills with translation and awareness of the importance of CRC testing.

In conclusion, this study analyzed and illustrated a model of the pathways among constructs leading to CRC screening among Chinese. By using structural equation modeling, the most likely linkages among constructs and the mediating factors can be examined. This model investigated how cultural, predisposing, enabling, access/satisfaction with health care, and health belief factors influenced CRC cancer screening. To our knowledge, our present study is one of the first studies to perform a path analysis with regard to factors that may lead to CRC screening.

There are several limitations to the study. First, these findings are based on self-reported questionnaires; second, because the sample was drawn from Chinese who participate in community organizations, the findings may not be generalizable to all Chinese Americans, especially those who do not participate in community-based organizations; and third, the study was focused on Chinese Americans and the findings may not be generalizable to other Asian ethnic groups in the U.S. It is also important to note that our model only explained $9 \%$ of the variance in colorectal cancer, and other unmeasured factors may be important to incorporate in future studies. In-depth exploration of cultural factors and health beliefs may provide further insight into variation in colorectal cancer screening. For example, Jerant, Fenton, and Franks (2008) found that after full adjustment in their models for age, gender, family annual income, education, insurance status, usual source of care, self-rated health, English spoken at home, and born in continental United States, Asian/non-Hispanic white disparities in colorectal cancer screening remained statistically significant. They conclude that "the implication is that unmeasured cultural factors may contribute to the Asian/non-Hispanic white disparity in CRC screening. Less acculturated Asian individuals in the United States may have core health beliefs and values that differ from those in the Western health model, leading them to decline FOBT or colonoscopy in the absence of worrisome symptoms. 
Future research will focus on further validation of the SCHBM on larger samples of Asian Americans that includes Chinese, Koreans, Vietnamese and Cambodians, using similar SEM analysis, to determine differences, if any, and similarities, among various ethnic groups that influence screening behavior in CRC. The ultimate goal is to reduce cancer screening disparities by using these findings to guide us to develop innovative and culturally appropriate intervention strategies for increasing CRC screening among diverse Asian Americans.

\section{Acknowledgements}

The authors wish to thank Asian Community Cancer Coalition partners, volunteers, community coordinators and research team at the Center for Asian Health, Temple University, who facilitated and supported the completion of the study. This research was supported by NIH grants UO1 CA114582 ATECAR-Asian Community Cancer Network (Grace X. Ma, $\mathrm{PhD}$, Principal Investigator) and by U54CA153513 Asian Community Cancer Health Disparity Center (Grace X. Ma, $\mathrm{PhD}$, Principal Investigator).

\section{References}

[1] Colorectal Cancer Facts \& Figures 2011-2013. Atlanta: American Cancer Society; 2011. Available from: http://www.cancer.org/Research/CancerFactsFigures/index. Accessed April 2, 2012.

[2] Wong ST, Gildengorin G, Nguyen T, Mock J. Disparities in colorectal cancer screening rates among Asian Americans and non-Latino whites. Cancer. 2005; 104(12): 2940-2947. PMid:16276538 http://dx.doi.org/10.1002/cncr.21521

[3] American Cancer Society. 2012. Available from:

http://www.cancer.org/docroot/CRI/content/CRI_2_4_3x_Can_Colon_and_rectum_cancer_be_found_early.asp. Accessed March 31 st, 2012.

[4] Centers for Disease Control and Prevention. Cancer Screening - United States, 2010. MMWR. 2012; 61(3). Available from: http://www.cdc.gov/mmwr/pdf/wk/mm6103.pdf. Accessed April 12, 2012

[5] Jerant AF, Fenton JJ, Franks P. Determinants of racial/ethnic colorectal cancer screening disparities. Arch Intern Med. 2008; 168(12): 1317-1324. PMid:18574089 http://dx.doi.org/10.1001/archinte.168.12.1317

[6] Maxwell AE, Crespi CM, Antonio CM, Lu P. Explaining disparities in colorectal cancer screening among five Asian ethnic groups: a population-based study in California. BMC Cancer. 2010; 10: 214. PMid:20482868 http://dx.doi.org/10.1186/1471-2407-10-214

[7] Beeker C, Kraft JM, Southwell BG, Jorgensen CM. Colorectal cancer screening in older men and women: qualitative research findings and implications for intervention. J Community Health. 2000; 25(3): 263-278. PMid:10868818 http://dx.doi.org/10.1023/A:1005104406934

[8] Mandelson MT, Curry SJ, Anderson LA, et al. Colorectal cancer screening participation by older women. Am J Prev Med. 2000; 19(3): 149-154. http://dx.doi.org/10.1016/S0749-3797(00)00193-8

[9] Sun WY, Basch CE, Wolf RL, Li XJ. Factors associated with colorectal cancer screening among Chinese-Americans. Prev Med. 2004; 39(2): 323-329. PMid:15226041 http://dx.doi.org/10.1016/j.ypmed.2004.04.029

[10] Choe JH, Tu S-P, Lim JM, Burke NJ, Acorda E, Taylor VM. "Heat in their intestine": colorectal cancer prevention beliefs among older Chinese Americans. Ethn Dis. 2006; 16: 248-254. PMid:16599379

[11] Tang TS, Solomon L J, McCracken L M. Barriers to fecal occult blood testing and sigmoidoscopy among older Chinese-American women. Cancer Practice. 2001; 9(6): 277-282. PMid:11879329 http://dx.doi.org/10.1046/j.1523-5394.2001.96008.x

[12] Copenhaver MM, Lee IC. Optimizing a community-friendly HIV risk reduction intervention for injection drug users in treatment: a structural equation modeling approach. J Urban Health. 2006; 83(6): 1132-1142. PMid:16933102 http://dx.doi.org/10.1007/s11524-006-9090-1

[13] Ebrahim SH, Anderson JE, Weidle P, Purcell DW. Race/ethnic disparities in HIV testing and knowledge about treatment for HIV/ AIDS: United States, 2001. AIDS Patient Care STDS. 2004; 18(1): 27-33. PMid:15006192 http://dx.doi.org/10.1089/108729104322740893

[14] Van Gelderen B, Van Heuven E, Veldhoven M, Zeelenberg M, Croon M. Psychological Strain and Emotional Labor among Police-Officers: A Diary Study. J Vocat Behav. 2007; 71(3): 446-459. http://dx.doi.org/10.1016/j.jvb.2007.09.001

[15] Wang MQ, Matthew RF, Bellamy N, James S. A structural model of the substance use pathways among minority youth. Am J Health Behav. 2005; 29(6): 531-541. PMid:16336108 http://dx.doi.org/10.5993/AJHB.29.6.8 
[16] Bunn JY, Bosompra K, Ashikaga T, Flynn BS, Worden JK. Factors influencing intention to obtain a genetic test for colon cancer risk: a population-based study. Prev Med. 2002; 34(6): 567-577. PMid:12052015 http://dx.doi.org/10.1006/pmed.2002.1031

[17] Loitman J, Leeman JM. Testing a mediational model of communication among medical staff and families of cancer patients. Structural Equation Modeling: A Multidisciplinary Journal. 2005; 12(3): 454-470. http://dx.doi.org/10.1207/s15328007sem1203_6

[18] Recklitis CJ, Parsons SK, Shih M-C, Mertens A, Robison LL, Zeltzer L. Factor structure of the brief symptom inventory-18 in adult survivors of childhood cancer: results from the childhood cancer survivor study. Psychol Assess. 2006; 18(1): $22-32$. PMid:16594809 http://dx.doi.org/10.1037/1040-3590.18.1.22

[19] Bentler PM. EQS Structural Equations Program Manual. Encino: Multivariate Software, Inc; 1995.

[20] Joreskog KG. Testing structural equation models. In: Bollen KAL, J.S., editor. Testing Structural Equation Models. Newbury Park: Sage Publications, 1993:294-316.

[21] Spoth R, Redmond C, Shin C. Direct and indirect latent-variable parenting outcomes of two universal family-focused preventive interventions: extending a public health-oriented research base. J Consult Clin Psychol. 1998; 66(2): 385-399. PMid:9583342 http://dx.doi.org/10.1037/0022-006X.66.2.385

[22] Ma GX, Shive ES, Gao W, Tan Y, Wang MQ. Prostate cancer screening among Chinese American men: A Structural Model. Am J Health Behav. 2012; 36(4): 495-504. PMid:22488399 http://dx.doi.org/10.5993/AJHB.36.4.6

[23] Sudman S, Bradburn NM. Asking Questions. San Francisco, CA: Jossey 1986.

[24] Muthén B, Muthén L. Integrating person-centered and variable-centered analysis: growth mixture modeling with latent trajectory classes. Alcohol Clin Exp Res. 2000; 24(6): 882-891. PMid:10888079 http://dx.doi.org/10.1111/j.1530-0277.2000.tb02070.x

[25] Bollen KA, Long JS. Testing Structural Equation Models. Newbury Park, CA: Sage; 1993.

[26] Coughlin SS, Uhler R. Breast and cervical cancer screening practices among Asian and Pacific Islander women in the United States, 1994-1997, Cancer Epidemiol Biomarkers Prev. 2000; 9: 597-603. PMid:10868695

[27] Juon H-S, Kim M, Shankar S, Han W. Predictors of adherence to screening mammography among Korean American women. Prev Med. 2004; 39(3): 474-481. PMid:15313086 http://dx.doi.org/10.1016/j.ypmed.2004.05.006

[28] Ellis JA, Metzger KB, Maulsby C, et al. Smoking among New York City Public High School Students. NYC Vital Signs. 2006; 5(1): $1-4$.

[29] Secginli S, Nahcivan N. Factors associated with breast cancer screening behaviors in a sample of Turkish women: a questionnaire survey. Int J Nurs Stud. 2006; 46: 161-171. PMid:16427965 http://dx.doi.org/10.1016/j.ijnurstu.2005.02.004

[30] Tang TS, Solomon LJ, McCracken LM. Cultural barriers to mammography, clinical breast exam, and breast self-exam among Chinese-American women 60 and older. Prev Med. 2000; 31(5): 575-583. PMid:11071839 http://dx.doi.org/10.1006/pmed.2000.0753

[31] Ward E, Jemal A, Cokkinides V, et al. Cancer Disparities by race/ethnicity and socioeconomic status. CA Cancer J Clin. 2004; 54(2): 78-93. PMid:15061598 http://dx.doi.org/10.3322/canjclin.54.2.78

[32] Ma GX, Shive SE, Fang CY, et al. Knowledge, attitudes, and behaviors of hepatitis B screening and vaccination and liver cancer risks among Vietnamese Americans. J Health Care Poor Underserved. 2007; 18(1): 62-73. PMid:17337798 http://dx.doi.org/10.1353/hpu.2007.0013

[33] Teng EJ, Friedman LC, Green CE. Determinants of colorectal cancer screening behavior among Chinese Americans. PsychoOncol. 2006; 15(1): 374-381.

[34] Taylor VM, Choe JH, Yasui Y, Li L, Burke N, Jackson JC. Hepatitis B awareness, testing, and knowledge among Vietnamese American men and women. J Community Health. 2005; 30(6): 477-490.

PMid:16370056 http://dx.doi.org/10.1007/s10900-005-7282-3

[35] Thompson MJ, Taylor VM, Yasui Y, et al. Hepatitis B knowledge and practices among Chinese Canadian women in Vancouver, British Columbia. Can J Public Health. 2003; 94(4): 281-286. PMid:12873087

[36] Steven Goldberg, S. Review of The inevitability of patriarchy. American Anthropologist. 1974; 76(2): 363-365. http://dx.doi.org/10.1525/aa.1974.76.2.02a00280 